\title{
Trends in alcohol prevalence, age of initiation and association with alcohol-related harm among South African youth: Implications for policy
}

\author{
Leane Ramsoomar, Neo K Morojele
}

Objectives. To understand alcohol use trends and alcohol-related harm among youth in South Africa (SA) between 1998 and 2008, and discuss implications for the current alcohol policy process.

Methods. A review was conducted of 4 national prevalence and 2 sentinel surveillance studies. Data were extracted to Epi Info (version 7) and chi-square analyses undertaken.

Results. Lifetime alcohol use remained stable but high at 20 25\% and 49.1 - 49.6\% according to South African Demographic and Health Survey (SADHS) and Youth Risk Behaviour Survey (YRBS) data, respectively. Age of initiation remained stable; $12 \%$ of adolescents initiated alcohol use prior to age 13 years. Significant gender differences existed with more males having ever consumed alcohol, engaged in binge drinking, and driven or walked under the influence of alcohol (DUI and WUI, respectively). Binge drinking among females increased significantly from $27 \%$ to $36 \%$ (SADHS) and $18 \%$ to $27 \%$ (YRBS). DUI and WUI increased. Homicide/ violence, suicide and unintentional deaths were significantly associated with blood alcohol concentration (BAC).

Conclusions. Although SA has made significant strides in alcohol control and prevention of alcohol-related harm over the past decade, early alcohol initiation remains a concern and binge drinking is increasing, especially among females. Significant associations exist between BAC and alcohol-related fatalities. Findings imply that regulatory policies are inadequate; additional efforts are required to ensure that control strategies translate into a reduction in harmful alcohol use by SA youth.

S Afr Med J 2012;102(7):609-612.
Globally, harmful alcohol use and associated risk behaviours present a formidable threat to the health of youth aged 15 - 29 years. In 2011 the World Health Organization reported that $9 \%$ of annual deaths in this age group were attributable to alcohol-related causes. ${ }^{1}$ In South Africa (SA) harmful alcohol use is of particular concern, with implications for violence, transport-related accidents and fatalities, homicide, suicide and unintentional deaths. ${ }^{2}$ Alcohol use among SA men - mainly binge drinking (consumption of $\geq 5$ drinks on 1 or more days) - is reported to be among the highest globally, ${ }^{1}$ corroborated by findings of a 2005 - 2008 national survey demonstrating increases in current, binge and hazardous drinking. ${ }^{3}$ Coupled with inordinate levels of alcohol-related harm, this has important implications for control and preventive policies in SA and calls into question the effectiveness of existing policies.

\section{Current alcohol policy in SA}

In a critical review of alcohol policy development processes in SA between 1994 and 2009, Parry succinctly described 4 policy initiatives of that period: ${ }^{4}$

Restrictions on alcohol advertising and counter-advertising were first considered in 1997, yet implementation was delayed for almost 12 years due to political decision-making and effecting changes to labelling by the alcohol industry.

The regulation of retail alcohol sales was complicated, as a legacy of apartheid resulted in $70 \%$ of liquor outlets being unlicensed.

School of Public Health, University of the Witwatersrand, Johannesburg Leane Ramsoomar, MHP

School of Public Health, University of the Witwatersrand, Johannesburg, and Alcohol and Drug Abuse Research Unit, Medical Research Council of South Africa Neo K Morojele, $\mathrm{PhD}$
The SA government was faced with bringing unlicensed outlets into the formal market and mediating among those responsible for implementing regulatory policy. The latter was complicated; each province had its own policy with varying levels of implementation, and consequently, of effectiveness.

Control of alcohol packaging. Flanagan et al., ${ }^{5}$ having shown the negative impact of the production and sale of cheap wine in the Western Cape winelands, recommended that bulk wine (packaged and sold in cheap non-self-supporting foil bags called papsakke) be brought under control. As a direct result, current law limits the capacity of alcohol containers to 5 litres and prohibits the sale of alcohol in papsakke. ${ }^{6}$

Increasing alcohol taxation is globally considered to be one of the most effective strategies in reducing alcohol consumption; a metaanalysis of 112 studies confirmed an inverse relationship between alcohol taxes and drinking. 7 SA government and industry, with their respective vested interests, resolved that taxes would be based on a proportion of the retail price, and would increase commensurate with increasing alcohol content. There has been a consistent increase in alcohol price since 2003, to reflect excise duty increases legislated by National Treasury; ${ }^{8}$ whether or not this has translated into a reduction in alcohol consumption is unclear.

Despite these efforts, alcohol-related road traffic accidents, violence, and injury are a growing concern in SA. Available data indicate that $32 \%$ and $40 \%$ of deaths in youth in 2002 and 2008 , respectively, were as a result of transport-related deaths, while the leading manner of death among those with a positive blood alcohol concentration (BAC) was violence. ${ }^{2}$ Harmful alcohol use also places youth at risk for a range of risky behaviours and intentional and unintentional injury and death.

Consideration of the trends in lifetime prevalence of alcohol use (age of initiation and patterns of drinking), the association thereof with alcohol-related harm and implications for regulatory policy has not, to the knowledge of the authors, been undertaken in SA. We employed data from 4 national prevalence surveys and 2 national sentinel surveillance studies with the aim of reviewing these trends 
among SA youth aged 13 - 19 years. In addition, we examined the association between BAC and alcohol-related harms. Findings were envisaged to inform future alcohol preventive and control policies.

\section{Methods}

Data were extracted from 4 national cross-sectional prevalence studies (South African Demographic and Health Survey (SADHS) $1998^{9}$ and $2003^{10}$ and Youth Risk Behaviour Study (YRBS) $2002^{11}$ and $2008^{12}$ ) and 2 national sentinel surveillance studies (National Injury and Mortality Surveillance Study (NIMSS) $2002^{2}$ and $2008^{13}$ ). Table 1 summarises the methods and characteristics of each study. Data on alcohol use and alcohol-related harms were extracted to Epi Info (version 7) for bivariate analyses.

\section{Results \\ Alcohol use trends in SA}

Lifetime alcohol use was stable but high from 1998 to 2008 (Table 2), as indicated by data from SADHS 1998 and 2003 (20\% and 25\%, respectively) and YRBS 2002 and 2008 (49.1\% and 49.6\%, respectively).

YRBS data on age of initiation, measured broadly as age of initiation of alcohol use prior to age 13 years, indicate that $12 \%$ of youth and significantly more males than females (15.8\% [13.5 - 18.0] v. $9.0 \%$ [ $7.4-10.4$ ] in 2002 and $15.3 \%$ [ 13.7 - 17.2] v. 8.6\% [6.8 - 10.8] in 2008) initiated alcohol use at this young age (Table 2).

Binge drinking was measured variably in each study. The terms 'risky' and 'hazardous or harmful' drinking were used in the 1998 and 2003 SADHS surveys, respectively; nevertheless they were uniformly defined as drinking $\geq 5$ standard alcoholic drinks per day for males and $\geq 3$ drinks per day for females. In our analysis, risky and harmful/hazardous drinking was defined as weekend drinking only, in line with episodic drinking patterns reported in studies nationally. In line with the YRBS studies, binge drinking was defined as the consumption of $\geq 5$ alcoholic drinks within a few hours on 1 or more days in the preceding month.

Significant gender differences emerged from the studies reviewed. According to YRBS data, more males than females reported binge
Table 2. Alcohol use trends

\begin{tabular}{clll}
\hline Study & $\begin{array}{l}\text { Lifetime } \\
\text { prevalence } \\
\%\end{array}$ & $\begin{array}{l}\text { Age of initiation } \\
<\mathbf{1 3} \text { years } \\
\%\end{array}$ & $\begin{array}{l}\text { Binge /risky } \\
\text { drinking } \\
\text { \% }\end{array}$ \\
\hline SADHS 1998 & 20.0 & N/A & N/A \\
$\quad$ Male & 25.3 & N/A & 24.1 \\
Female & 15.0 & N/A & 27.3 \\
SADHS 2003 & 25.0 & N/A & N/A \\
Male & 32.0 & N/A & 9.3 \\
Female & 17.0 & N/A & 36.6 \\
YRBS 2002 & 49.1 & 12.0 & 23.0 \\
Male & 56.1 & 15.8 & 29.3 \\
Female & 43.5 & 9.0 & 17.9 \\
YRBS 2008 & 49.6 & 12.1 & 28.5 \\
Male & 54.4 & 15.3 & 33.5 \\
Female & 45.1 & 8.6 & 23.7
\end{tabular}

SADHS = South African Demographic and Health Survey; YRBS = Youth Risk Behaviour Survey; N/A = not available.

drinking $(29.3 \%$ [26.7 - 31.9] v. $17.9 \%$ [15.6 - 20.3], respectively, in 2002 , and $33.5 \%$ [ $30.8-36.4$ ] v. $23.7 \%$ [ 21.1 - 26.6], respectively, in 2008). ${ }^{11,12}$ In contrast, more females than males reported binge drinking according to SADHS data $(27.3 \%$ v. $24.1 \%$, respectively, in 1998 and $36.3 \%$ v. 9.6\%, respectively, in 2003). Overall, females showed the greatest increase in binge drinking, from $27.3 \%$ to $36.6 \%$ in the SADHS 1998 and 2003 surveys, and $17.9 \%$ to $23.7 \%$ in the YRBS 2002 and 2008 surveys, respectively.

\section{Alcohol-related traffic safety}

Given the association between alcohol use and traffic fatalities, ${ }^{3}$ we reviewed traffic risks associated with alcohol use, including driving and walking along the road under the influence of alcohol (DUI and WUI, respectively). Only the YRBS studies reported alcohol-related traffic safety.

Table 1. Summary of the studies included in this review

\begin{tabular}{|c|c|c|c|c|c|}
\hline Study & Survey type & Design & Age group (years) & Sample size & Variables \\
\hline SADHS 1998 & National household & Cross-sectional & $15-19$ & 13826 & $\begin{array}{l}\text { Prevalence, age of } \\
\text { initiation, binge drinking/ } \\
\text { risky drinking }\end{array}$ \\
\hline SADHS 2003 & National household & Cross-sectional & $15-19$ & 10214 & $\begin{array}{l}\text { Prevalence, age of } \\
\text { initiation, binge drinking/ } \\
\text { risky drinking }\end{array}$ \\
\hline YRBS 2002 & National school & Cross-sectional & $13-19$ & 10699 & $\begin{array}{l}\text { Prevalence, age of } \\
\text { initiation, binge drinking, } \\
\text { driving/walking under the } \\
\text { influence of alcohol }\end{array}$ \\
\hline YRBS 2008 & National school & Cross-sectional & $13-19$ & 10270 & $\begin{array}{l}\text { Prevalence, age of } \\
\text { initiation, binge drinking, } \\
\text { driving/walking under the } \\
\text { influence of alcohol }\end{array}$ \\
\hline NIMSS 2002 & Sentinel surveillance & $\begin{array}{l}\text { Surveillance/cross- } \\
\text { sectional }\end{array}$ & $15-19$ & $849^{*}$ & $\begin{array}{l}\text { BAC, alcohol-relatedness } \\
\text { of non-natural deaths }\end{array}$ \\
\hline NIMSS 2008 & Sentinel surveillance & $\begin{array}{l}\text { Surveillance/cross- } \\
\text { sectional }\end{array}$ & $15-19$ & $672^{*}$ & $\begin{array}{l}\text { BAC, alcohol-relatedness } \\
\text { of non-natural deaths }\end{array}$ \\
\hline
\end{tabular}


Between 2002 and 2008 there was an overall increase in DUI and WUI among youth. The $7.8 \%$ reported prevalence of DUI among youth in 2002 increased to $25.9 \%$ in $2008 .{ }^{11,12}$ Gender differences were significant, with more males than females reporting DUI $(10.2 \%$ [8.7 - 11.6] v. $5.5 \%$ [ 3.7 - 7.2], respectively, in 2002 , increasing to $29 \%$ [26.4 - 32.2] v. $18 \%$ [14.1 - 22.7], respectively, in 2008). There was a marked increase in the reported prevalence of WUI among youth, from $10.6 \%$ in 2002 to $18.1 \%$ in 2008 . Significantly more males than females reported WUI $(14.9 \%[8.7$ - 11.6] v. $7.1 \%$ [3.7 - 7.3], respectively, in 2002 and $23.4 \%$ [21.7 - 25.2] v. $13 \%$ [11.5 - 14.7], respectively, in 2008).

\section{Alcohol relatedness of death among youth}

The NIMSS surveys reported alcohol-related deaths among children and youth according to BAC. Between 2002 and 2008 an overall increase from $38 \%$ to $43 \%$ was reported in the alcohol-relatedness of non-natural deaths. A marked increase was observed in average BAC among those who were alcohol-positive (from $0.0569 \mathrm{~g} / \mathrm{mmol}$ in 2002 to $0.14 \mathrm{~g} / \mathrm{mmol}$ in 2008). ${ }^{2,13}$ Overall, stark gender differences existed with regard to alcohol-relatedness of deaths: $40 \%$ of males and $31 \%$ of females tested BAC-positive in 2002, while $80 \%$ of males and $20 \%$ of females were BAC-positive in 2008.

\section{Alcohol relatedness and alleged manner of death}

Table 3 summarises the proportion of BAC-positive cases among youth aged 15 - 19 years according to alleged manner of death between 2002 and 2008: violence/homicide-related deaths increased nonsignificantly from $50 \%$ to $54 \%$; transport-related deaths increased marginally significantly from $32 \%$ to $40 \%$; suicide cases remained stable at $17 \%$; undetermined deaths increased non-significantly from $29 \%$ to $31 \%$; and the most dramatic and statistically significant increase was seen in unintentional deaths from $18 \%$ to $31 \%$.

\section{BAC and alleged manner of death}

Table 4 summarises the results of chi-square analyses between BAC and non-natural manners of death in the 2002 and 2008 review periods. Among alcohol-positive cases, we compared the proportion of those who did or did not die for each manner of death. In 2002 there was a significant association between positive BAC and risk of violent death, with $50 \%$ of violent/homicide cases testing alcoholpositive $(p<0.001)$; the same held true for $2008(p<0.001)$. In 2002 unintentional deaths were significantly associated with positive BAC $(p<0.001)$. However, suicide cases were less likely to be alcoholpositive than non-suicide cases $(p<0.001)$.

\section{Discussion}

We reviewed trends in lifetime use, age of initiation, binge drinking tendency and alcohol-related harm among SA youth aged $13-19$
Table 3. Positive BAC cases according to alleged manner of death

\begin{tabular}{|c|c|c|c|}
\hline $\begin{array}{l}\text { Alleged manner } \\
\text { of non-natural } \\
\text { death }^{*}\end{array}$ & $\begin{array}{l}\text { NIMMS } 2002 \\
(N=849) \\
\%\end{array}$ & $\begin{array}{l}\text { NIMMS } 2008 \\
(N=672) \\
\%\end{array}$ & Chi-square \\
\hline Homicide/violence ${ }^{\dagger}$ & 50 & 54 & 1.28 \\
\hline Suicide ${ }^{\ddagger}$ & 17 & 17 & 0.00 \\
\hline Transport & 32 & 40 & $2.46(p<0.010)$ \\
\hline Unintentional $^{5}$ & 18 & 31 & $2.96(p<0.001)$ \\
\hline Undetermined & 29 & 31 & 0.06 \\
\hline
\end{tabular}

NIMMS = National Injury Mortality Surveillance System

* NIMSS definition: all deaths not or possibly not due to natural causes, and which, by law, require medico-legal investigation.

${ }^{\dagger}$ NIMSS definition: 'Intentional injuries inflicted by another person (perpetrator). This definition excludes deaths due to culpable homicide since the NIMSS data are geared towards prevention initiatives, and intentional and unintentional injuries require different types of
intervention.

${ }^{\text {F}}$ Self-inflicted intentional injuries resulting in fatality.

${ }^{\S}$ All other unintentional non-transport related injuries, such as burns, falls, poisoning and drowning.

'Deaths where the medical examiner is unable to determine whether the cause of death was violence/homicide, suicide, transport, unintentional injury or natural.

years between 1998 and 2008. Associations between alcohol use and related harms were examined, and findings in light of both preventive and control policies discussed.

SA is considered to be a medium consumption country in terms of per capita adult alcohol consumption. However, findings from national surveys show that those who do drink appear to do so at binging levels ( $\geq 5$ drinks in one sitting). ${ }^{3}$ Consistent with global findings, alcohol use is taking on a youthful face, as indicated by an increasing trend in lifetime prevalence of alcohol use among youth aged $13-19$ years. The number of youth aged $<13$ years initiating alcohol use remained stable at $12 \%$ between 2002 and 2008; in real terms this translates to approximately 10000 youth per review period. This is particularly important, given that early initiation of alcohol use is associated with substance use problems later in life. While overall alcohol use may have remained stable, binge drinking increased markedly, most notably, among females. These findings have serious implications for youth morbidity and mortality, indicated by the rising rates of alcohol-related traffic risks and related mortality. ${ }^{2,11-13}$ The increases in non-natural deaths of BAC-positive youth in 2002 and 2008 highlight growing alcohol-related harm; it is clear that current policy efforts to minimise such harm are inadequately affected.

Global burden of disease and alcohol-attributable injury statistics indicate that alcohol-related disease burden operates in 2 dimensions via average volume of alcohol consumed, and patterns of drinking (mainly binge drinking). The former is associated with chronic health

Table 4. Chi-square analysis of BAC and alleged manners of death among youth aged 15 - 19 years

\begin{tabular}{|c|c|c|c|c|}
\hline \multirow[b]{2}{*}{ Alleged manner of non-natural death } & \multicolumn{2}{|c|}{ NIMMS $2002(N=849)$} & \multicolumn{2}{|c|}{ NIMMS $2008(N=672)$} \\
\hline & $n(\%)$ & Chi-square & $n(\%)$ & Chi-square \\
\hline Homicide/violence & $221(50)$ & $56.335^{*}$ & $181(54)$ & $33.274^{*}$ \\
\hline Suicide & $17(17)$ & $21.512^{*}$ & $15(17)$ & $27.547^{*}$ \\
\hline Transport & $58(32)$ & 3.649 & $66(40)$ & 1.010 \\
\hline Unintentional & $16(18)$ & $16.057^{*}$ & $17(31)$ & 3.492 \\
\hline Undetermined & $12(29)$ & 1.444 & $8(31)$ & 1.614 \\
\hline
\end{tabular}


issues such as cancer or ischaemic heart disease, while the latter is associated with acute problems such as interpersonal violence and injuries. ${ }^{15}$ These associations are borne out in this review. Specifically, the data sources employed revealed increases in binge drinking patterns and accompanying increases in traffic-related deaths (DUI and WUI), homicides and unintentional deaths. One explanation for this is that heavy episodic drinking acts physiologically to impair motor function and psychologically to lower inhibitions, resulting in greater risk-taking behaviour. Young people, whose threshold for large amounts of alcohol may be lower given their smaller body sizes, are particularly vulnerable. Contributing to binge drinking among SA youth is the high availability and accessibility of alcohol. This review indicated that large numbers of minors $(<18$ years) are drinking despite efforts to reduce alcohol availability to minors by increasing taxation and legislating liquor outlet registration.

Also revealed is that youth drinking patterns are changing, although there is no apparent change in the age of initiation or the proportion of drinkers. Plausible explanations for these trends lie in the areas of access, poor community policing, large-scale youth-specific marketing, advertising and affordable price of alcoholic beverages. Moreover, the risk for youth drinking, and binge drinking, is exacerbated by environmental stressors such as poverty, unemployment and crime, while poor communities, as consumers, producers and retailers of alcohol, are permissive of potential alcohol abuse by SA youth.

Middle- to high-income youth are equally vulnerable through youthspecific marketing strategies. SA youth are targeted by an alcohol industry determined to explore a previously untapped market. Marketing has been overt, through the promotion of alcoholic beverages at sporting events and happy hours, and subliminal, targeting youth and women with so-called 'malternatives ${ }^{14}$ to alcohol such as 'alcopops ${ }^{14}$ and sweetened, fruity drinks. Popular media and adverts continue to portray alcohol use as associated with fun, success and popularity.

Together these findings have important implications for a range of policies, including the 4 strategies adopted in 1997 - 2009, ${ }^{4}$ aimed at reducing alcohol-related harms. One strategy to reduce alcohol availability - and consequently consumption - via stronger community policing and enforcement of legislation that should be extended to commuters and pedestrians who display public drunkenness. Regulation of sale and access to minors would limit accessibility by reducing the number of outlets where alcohol is sold. ${ }^{15} \mathrm{~A}$ number of studies have demonstrated that a reduction in the number/density of alcohol outlets is associated with a reduction in alcohol-related harms, especially violence. ${ }^{16}$ Traffic risks associated with WUI and DUI should be a call to action to prioritise drink-driving/walking countermeasures, including globally recommended unscheduled sobriety checks and stringent limits on new drivers $(0.00 \mathrm{~g} / 100 \mathrm{ml})$ for the first 3 years after obtaining a driver's licence. ${ }^{15}$
Awareness of the role of alcohol harm to others, accruing from drunk driving, domestic violence and psychological stress to family members, has not been adequately highlighted. As a result, the full burden of alcohol (ab)use on society is probably underestimated.

The consistent implementation of the alcohol taxation policy in SA in the last decade, while laudable, will not, singularly, result in a reduction in alcohol use and associated harm among the youth. A joint and concerted effort by policy makers, implementers, lobbyists and civil society groups is required to minimise early-onset alcohol use and binge drinking tendencies, and, thereby, alcohol-related harms.

Acknowledgements. We thank Hilton Donson and Annelise Krige of the Medical Research Council and the University of South Africa's Safety \& Peace Promotion Research Unit (SAPPRU) for provision of the NIMSS data. We acknowledge SADHS 1998/2003 data from the Department of Health, and the MRC Health Promotion and Development Research Unit for YRBS 2002/2008 data. Special thanks are due to the Carnegie Corporation Transformation Programme at the University of the Witwatersrand for funding to support the writing of this manuscript.

\section{References}

1. World Health Organization. Global Status Report on Alcohol and Health. Geneva: WHO, 2011.

2. MRC Crime, Violence and Injury Lead Programme. A Profile of Fatal Injuries in South Africa. Fourth Annual Report of the National Injury Mortality Surveillance System. Pretoria: MRC, 2003.

3. Peltzer K, Davids A, Njuho P. Alcohol use and problem drinking in South Africa: findings from a national population-based survey. Afr J Psychiatry 2011;14:30-37. [http://dx.doi.org/10.4314/ajpsy.v14i1.65466] 4. Parry CDH. Alcohol policy in South Africa: A review of policy development processes between 1994 2009. Addiction 2010;105:1340-1345. [http://dx.doi.org/10.1111/j.1360-0443.2010.03003.x]

5. Flanagan V, Schoenberg C, Lomofsky D. Final Report: Study to Examine the Impact of the Production and Sale of Cheap Wine in South Africa. Pretoria: National Agricultural Marketing Council, 2002.

6. Department of Agriculture. Amendment to Liquor Products Act 60 of 1989. Pretoria: Department of Agriculture, 2007.

7. Anderson P, Bruijn AD, Angus K, Gordon R, Hastings G. Impact of alcohol advertising and media Anderson $\mathrm{P}$, Bruijn $\mathrm{AD}$, Angus K, Gordon R, Hastings G. Impact of alcohol advertising and media
exposure on adolescent alcohol use: A systematic review of longitudinal studies. Alcohol and Alcoholism 2009;44:229-243. [http://dx.doi.org/10.1093/alcalc/agn115]

8. South African Revenue Service. Tax Proposals: Budget 2011. Pretoria: SARS, 2011

8. South African Revenue Service. Tax Proposals: Budget 2011. Pretoria: SARS, 2011.
9. Department of Health, Medical Research Council. South Africa Demographic and Health Survey 1998. Pretoria: $\mathrm{DoH}, 2003$.
19epartment of

10. Department of Health, Medical Research Council, OrcMacro. South Africa Demographic and Health Survey 2003. Pretoria: DoH, 2007

11. Reddy SP, Panday S, Swart D, et al. Umthenthe uhlaba usamila - the $1^{\text {st }}$ South African youth risk behaviour survey 2002. Pretoria: DoH, 2002. http://www.mrc.ac.za/healthpromotion/YRBSpart1.pdf (accessed 20 May 2012).

12. Reddy SP, James S, Sewpaul R, et al. Umthente Uhlaba Usamila - The $2^{\text {nd }}$ South African Youth Risk Behaviour Survey 2008. Pretoria: DoH, 2010. http://www.mrc.ac.za/healthpromotion/yrbs_2008_ final_report.pdf (accessed 20 May 2012).

13. MRC Crime, Violence and Injury Lead Programme. A Profile of Fatal Injuries in South Africa: Tenth Annual Report 2008 of the National Injury Mortality Surveillance System. Pretoria, MRC: 2010.

4. American Medical Association. Girlie drinks... women's diseases. Chicago, IL: AMA, 2004. http://www. american Medical Association. Girlie drinks... Womens diseases. Chicago, IL: AMA 2012 .
alcoholpolicymd.com/pdf/girlie_drinks_survey\%20.pdf (accessed 20 May 2012).

alcoholpolicymd.com/pdf/girlie_drinks_survey\%20.pdf (accessed 20 May 2012). University Press, 2010. [http://dx.doi.org/10.1093/acprof:oso/9780199551149.001.0001]
U.

16. Gruenewald PJ, Remer L. Changes in outlet densities affect violence rates. Alcoholism: Clinical and Experimental Research 2006;30:1184. [http://dx.doi.org/10.1111/j.1530-0277.2006.00141.x] 